\title{
PEMBERDAYAAN PETANI MELALUI PELATIHAN UJI CITA RASA UNTUK MENINGKATKAN KUALITAS KOPI
}

\author{
Umar Dani, Sri Ayu Andayani \\ Universitas Majalengka \\ ud_umardani@yahoo.co.id
}

\begin{abstract}
Farmer empowerment through taste testing training aims to improve farmers' knowledge, attitudes and skills, so that the quality of coffee can improve. This activity was carried out in the Sugih Jaya Farmer Group in Lemah Village, Sugih in Lemah Sugih District, Majalengka Regency on June 28, 2019. The method used was participatory training (theory and practice) of taste testing. The material provided includes the role of taste tests for quality control, processing and their effects on taste, factors influencing steeping, basics of organoleptic testing, and characteristics and description of tastes. The results of the activities showed that the training participants were very enthusiastic and played an active role in participating in the activity, so that their knowledge, attitudes and skills about coffee flavor testing could increase.
\end{abstract}

Keywords: empowerment, farmers, taste testing, coffee quality.

\begin{abstract}
Abstrak
Pemberdayaan petani melalui pelatihan uji cita rasa ini bertujuan untuk meningkatkan pengetahuan, sikap dan keterampilan petani, sehingga kualitas kopi dapat meningkat. Kegiatan ini dilaksanakan di Kelompok Tani Sugih Jaya Desa Lemah, Sugih Kecamatan Lemah Sugih, Kabupaten Majalengka pada tanggal 28 Juni 2019. Metode yang digunakan adalah pelatihan partisipatif (teori dan praktek) uji cita rasa. Materi yang diberikan antara lain peranan uji cita rasa untuk pengendalian mutu, pengolahan dan pengaruhnya terhadap cita rasa, faktor-faktor yang berpengaruh terhadap seduhan, dasar-dasar uji organoleptik, dan karakteristik dan deskripsi cita rasa. Hasil kegiatan memperlihatkan bahwa peserta pelatihan sangat antusias dan berperan aktif dalam mengikuti kegiatan, sehingga pengetahuan, sikap dan keterampilan tentang uji cita rasa kopi dapat meningkat.
\end{abstract}

Kata Kunci: pemberdayaan, petani, uji cita rasa, kualitas kopi.

\section{Pendahuluan}

Kopi (Coffea spp.) merupakan komoditas perkebunan dan industri tropis utama yang diperdagangkan di seluruh dunia dengan kontribusi hampir setengah dari total ekspor komoditas tropis (Pusdatin Pertanian, 2016). Dalam perdagangan kopi dikenal istilah "Specialty Coffee" yaitu kopi yang memiliki cita rasa terbaik, aroma khas dan unik, tingkat kerusakan biji rendah. Biasanya berasal dari jenis Arabika dan varietas tertentu serta berasal kawasan geografis yang beriklim mikro istimewa dan proses pengolahan yang baik serta diberi nama sesuai daerah asal kopi tersebut diproduksi (Yusianto, 2017; coffeeland, 2016; Otten Coffee, 2016). Specialty Coffee Association of America (SCAA) mengategorikan kopi spesial jika bernilai 80 atau lebih pada skala 100 poin (SCAA, 2015).

Tren perdagangan kopi dunia maupun dalam negeri pada saat ini, memperlihatkan bahwa permintaan terhadap "Specialty Coffee" cenderung meningkat, karena kopi sudah 
menjadi bagian dari gaya hidup masyarakat (Ekonomi Bisnis, 2016). Indonesia dikenal sebagai salah satu produsen "Specialty Coffee" terbaik (okezone.com, 2016). Tercatat ada 24 jenis kopi yang termasuk kategori "Specialty Coffee" (Indikasi geografis terdaftar, 2016). Namun, produksinya masih terbatas, sehingga akan menjadi potensi terbesar bagi pengembangan kopi Indonesia.

Saat ini, tuntutan konsumen terhadap "Specialty Coffee" meliputi mutu, konsistensi dan kesinambungan produksi. Mutu biji kopi yang baik, secara fisik dilihat berdasarkan persentase kerusakan atau cacat, sedangkan aroma dan cita rasa diketahui dengan uji cita rasa (cupping). Uji cita rasa kopi adalah keterampilan kunci dalam pengendalian mutu dan menjadi penting dalam perdagangan kopi. Menurut Yusianto (2019) bahwa uji cita rasa adalah metode sistematik dalam mengevaluasi karakteristik aroma dan rasa kopi. Bagi produsen uji cita rasa berguna untuk mengetahui mutu, konsistensi, kerusakan atau cacat dari pengolahan, menentukan harga jual, dan perbaikan metode pengolahan. Dengan demikian, kegiatan uji cita rasa tidak terpisahkan dalam sistem produksi (Iccri, 2016).

Berdasarkan latar belakang tersebut, maka pemberdayaan petani melalui pelatihan ini sangat penting untuk meningkatkan pengetahuan, sikap dam keterampilan petani, sehingga kualitas kopi dapat meningkat.

\section{Metode}

Kegiatan ini telah dilaksanakan di Kelompok Tani Sugih Jaya Desa Lemah Sugih, Kecamatan Lemah Sugih, Kabupaten Majalengka pada tanggal 28 Juni 2019. Peserta dalam kegiatan ini adalah anggota aktif Kelompok Tani Sugih Jaya yang berjumlah tiga puluh orang petani.

Bahan yang digunakan adalah roasted coffee been dan air panas. Alat-alat yang yang digunakan adalah Flavor note wheel, grinder, cupping bowl, cupping spoon, coffee cupping sample, timbangan digital, teko, pemanas air, dan kompor.

Metode yang digunakan adalah pelatihan partisipatif (teori dasar dan praktek) uji cita rasa. Materi yang diberikan antara lain, peranan uji cita rasa untuk pengendalian mutu, pengolahan dan pengaruhnya terhadap cita rasa, faktor-faktor yang berpengaruh terhadap seduhan, dasar-dasar uji organoleptik, dan karakteristik dan deskripsi cita rasa.

Karakteristik kopi yang dinilai adalah sweetness (rasa manis yang dimiliki kopi), acidity (keasaman yang dikategorikan sebagai sour atau asam sekali, enak atau crispy/juiciness), mouthfeel (rasa ringan, lembut, sensasi penuh di mulut, baik mirip seperti the, coklat atau lebih terasa kaya, creamy dan heavy), flavor (mengecap, merasa macam-macam rasa kopi dan aroma dari satu jenis kopi tertentu, tapi juga seberapa menyenangkan rasa kopi).

\section{Hasil dan Pembahasan}

Jumlah peserta yang hadir sebanyak tiga puluh orang. Materi teori dasar uji cita rasa terdiri dari peranan uji cita rasa untuk pengendalian mutu, pengolahan dan pengaruhnya terhadap cita rasa, faktor-faktor yang berpengaruh terhadap seduhan, dasar-dasar uji organoleptik, karakteristik dan deskripsi cita rasa disampaikan oleh Tim yang berasal dari Sustainable Coffee Platform Indonesia (SCOPI) dan Fakultas Pertanian Universitas Majalengka. 
Peserta, pemateri dan instruktur pelatihan pada saat penyampaian materi dapat dilihat pada Gambar 1, 2 dan 3.

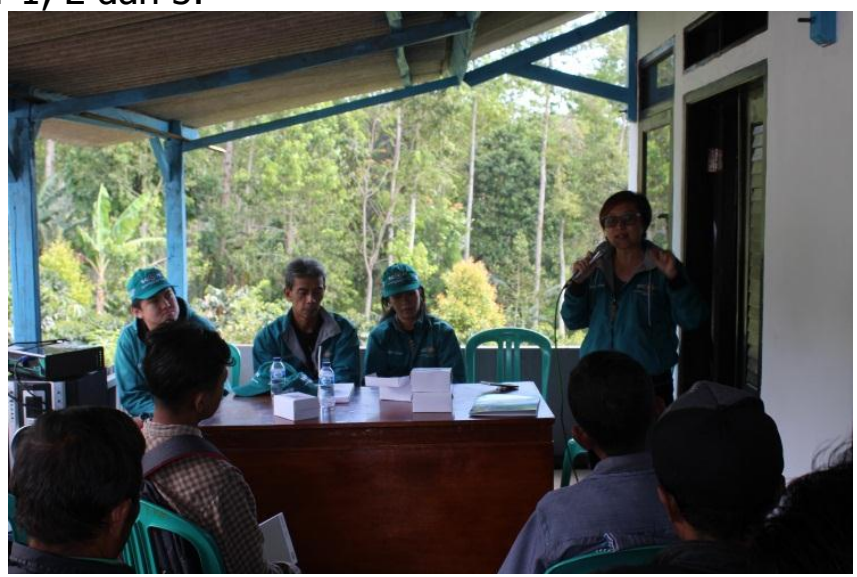

Gbr 1. Ibu Veronika dan Tim (SCOPI) sedang menyampaikan materi

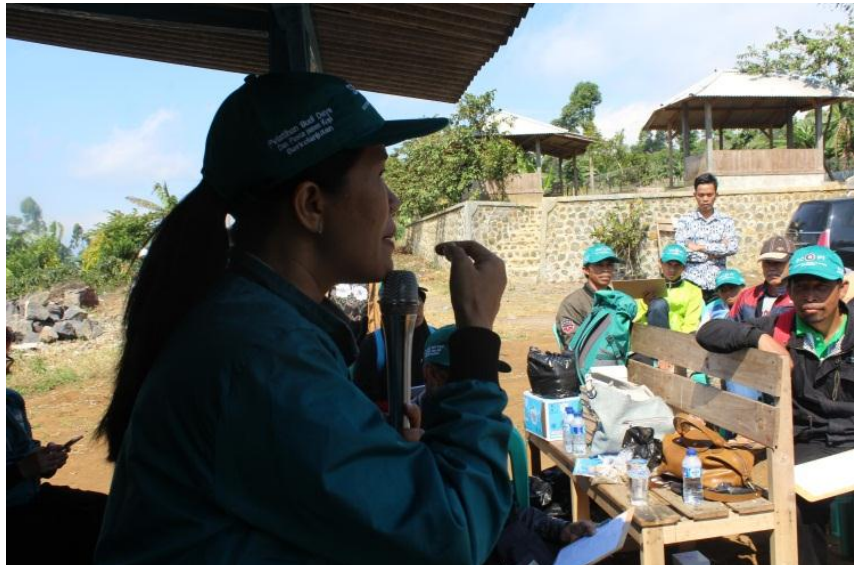

Gbr 2. Instruktut (SCOPI sedang menyampaikan materi.

Gambar 1 dan 2 memperlihatkan pemateri dan instruktur menyampaikan materi dengan penuh antusias, jelas, komunikatif, dan sangat menguasai materi yang disampaikan. Materi disampaikan menggunakan media slide (power point) dan alat peraga.

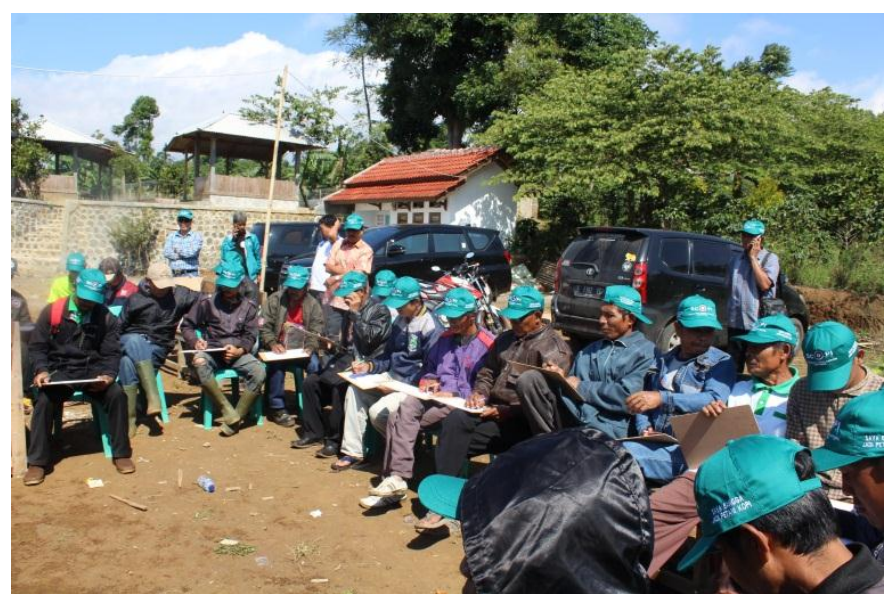

Gbr 3. Peserta Pelatihan sedang menyimak materi. 


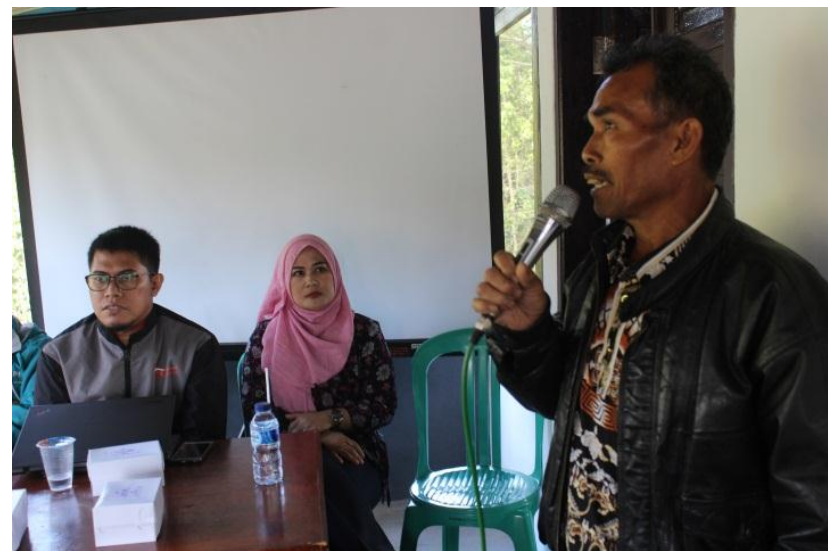

Gbr 4. Peran aktif peserta dalam menyampaikan pendapat.

Respon peserta pelatihan pun sama sangat antusias dan tertarik dengan materi pelatihan yang disampaikan. Hal ini terlihat dari adanya proses diskusi partisipatif dari peserta untuk menanyakan atau memberikan komentar sesuai pengetahuan dan pengalamannya secara empirik (Gambar 4).

Penyampaian materi praktek uji rasa disampaikan oleh instruktur dari Tim SCOPI dan Faperta UNMA. Demonstrasi dan praktek ini dilakukan dengan tahapan-tahapan sebagai berikut : 1) persiapan alat dan bahan praktek yang dipandu oleh intruktur dari Tim SCOPI dan Faperta UNMA; 2) pengaturan tata laksana uji cita rasa pada meja peraga; 3) penimbangan biji kopi yang sudah disangrai (roasted coffee been) sebanyak $8,25 \mathrm{~g}$ per $150 \mathrm{ml}$ air, kemudian dilakukan proses pengilingan roaster dengan menggunakan grinder hingga kehalusan medium coarse atau medium; 4) pengujian aroma kopi sebelum diseduh, kemudian hasilnya dicatat pada flavor note wheel; 5) Proses menyeduh $8,25 \mathrm{~g}$ kopi halus dengan air panas $96^{\circ} \mathrm{C}$ yang sudah dipersiapkan dan diamkan selama 4 menit, kemudian cium kembali aroma kopi setelah diseduh dan catat pada flavor note wheel; 6) kopi bubuk yang ada di permukaan dipinggirkan menggunakan cupping spoon, kemudian cium aroma dan catat pada flavor note wheel. 7) bubuk kopi di permukaan dipindahkan ke wadah lain, kemudian ambil satu cupping spoon air seduhan, sesap hingga memenuhi mulut dan catat pada flavor note wheel; 8) ulangi hingga puas dengan hasilnya.

Pada sesi praktek ini, instruktur menyampaikan materi dengan antusias, jelas, komunikatif, dan sangat menguasai materi sesuai keahliannya dalam memperagakan uji cita rasa di hadapan peserta pelatihan (Gambar 5, dan 7.

Respon peserta pelatihan pun sangat antusias dan tertarik dengan materi demonstrasi dan praktek yang disampaikan instruktur. Hal ini terlihat dari aktivitas peserta yang secara aktif mengikuti praktek sesuai dengan arahan instruktur (Gambar 6, 8 dan 9).

Rata-rata hasil uji cita rasa dari tiga puluh peserta pelatihan adalah sebagai berikut : fragran/aroma $=7,25$, flavor $=7,50$, aftertaste $=7,00$, acidity $=7,25$, body $=$ 8,00 , uniformity $=10,00$, balance $=7,25$, clean up $=10,00$, sweetness $=10,00$, over all $=7,50$, maka skore akhir $=81,75$.

Hasil uji cita rasa ini dibandingkan dengan hasil uji cita rasa yang dihasilkan oleh para intruktur (SCOPI) yang sudah bersertifikat atau kompeten dalam uji cita rasa. Ratarata hasil uji cita rasa yang dihasilkan oleh para instruktur yaitu 80,95.

Perbadingan hasil uji cita rasa yang dilaksanakan petani dengan instruktur, selisihnya tidak berbeda nyata. 


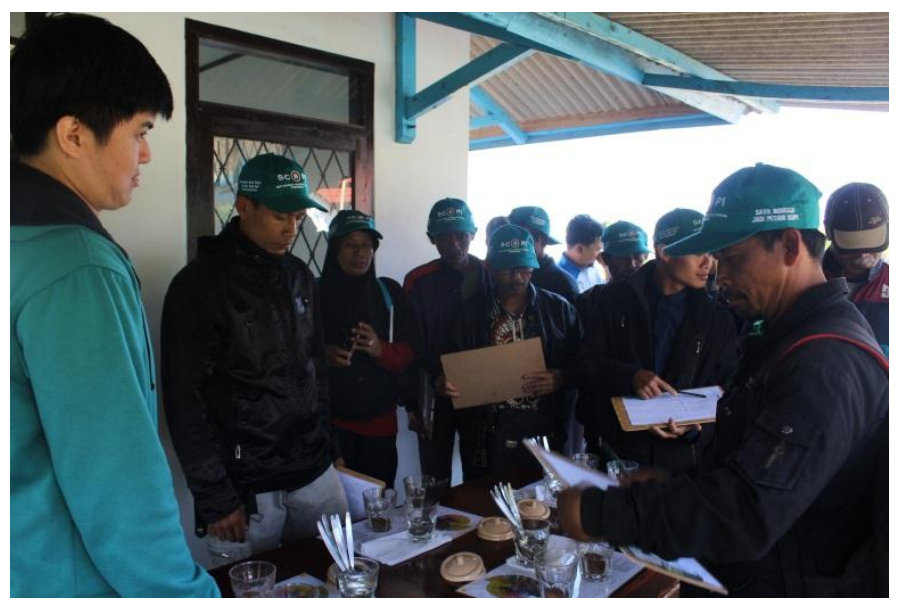

Gbr 5. Instruktur menjelaskan tahapan Uji Cita Rasa.

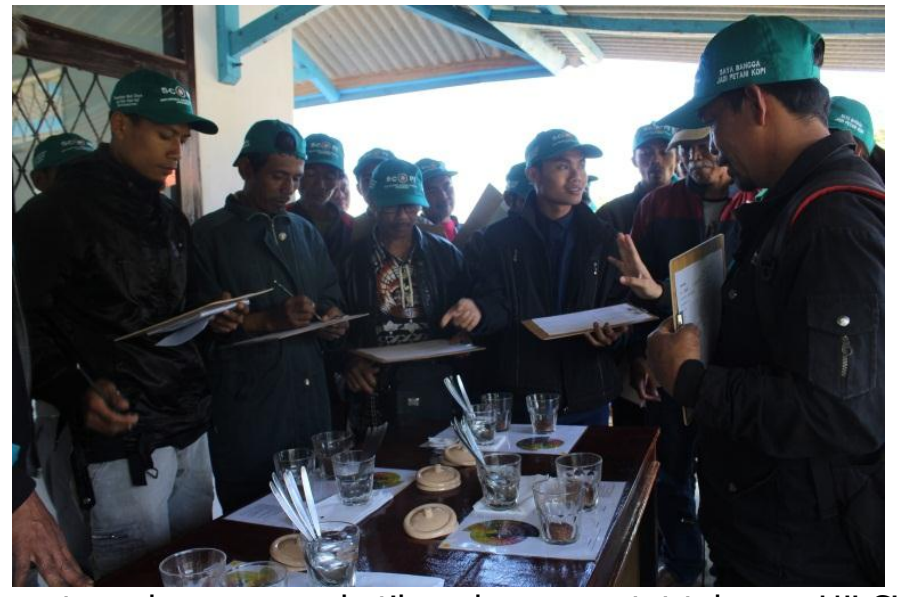

Gbr 6. Peserta sedang menperhatikan dan mencatat tahapan Uji Cita Rasa.

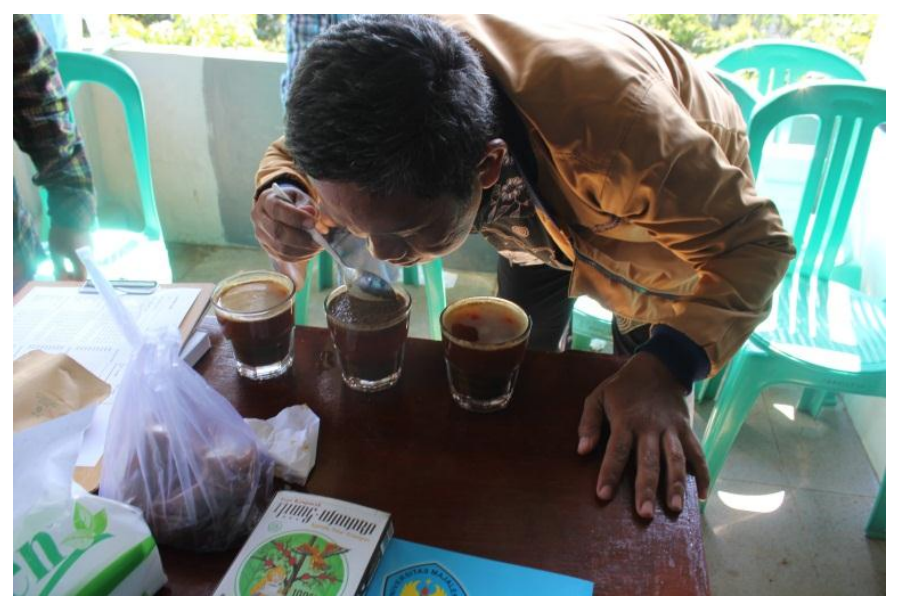

Gbr 7. Instruktur sedang memperagakan Uji Cita Rasa. 


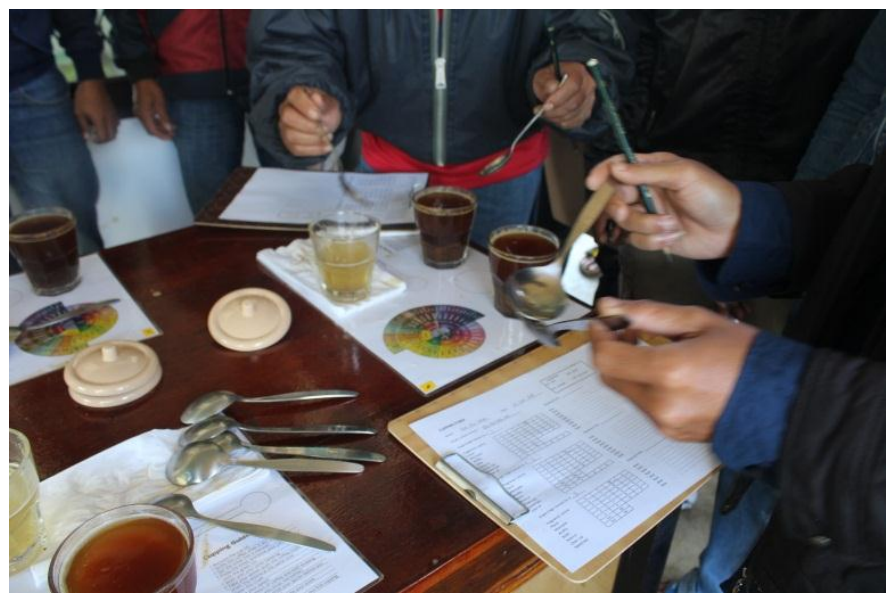

Gbr 8. Peserta dipandu instruktur sedang praktek Uji Cita Rasa.

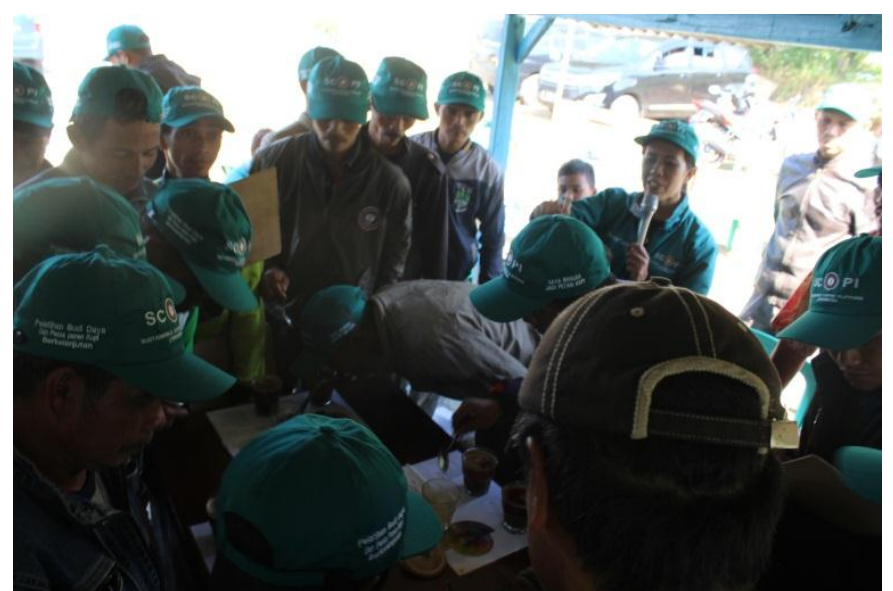

Gbr 9. Peserta dipandu instruktur sedang mempraktekan Uji Cita Rasa.

\section{Kesimpulan}

Berdasarkan hasil dan pembahasan dapat ditarik kesimpulan bahwa peserta pelatihan sangat antusias dan berperan aktif dalam mengikuti kegiatan, sehingga pengetahuan, sikap dan keterampilan tentang uji cita rasa kopi meningkat. Upaya meningkatkan mutu, konsistensi, mengurangi kerusakan atau cacat dari pengolahan, keberdayaan petani dalam menentukan harga jual, dan perbaikan metode pengolahan, maka penyebarluasan pengetahuan, sikap dan keterampilan petani tentang uji cita rasa kopi perlu dilakukan pada anggota kelompok lainnya.

\section{Daftar Pustaka}

COFFEELAND, 2016. Kopi Specialty vs Kopi Commercial. https://coffeeland.co.id/kopispecialty-vs-kopi-commercial/ Diakses 5 juli 2019.

EKONOMI BISNIS, 2016. Peluah Usaha Specialty Coffee Jadi Potensi Pengembangan di Indonesia. https://ekonomi.bisnis.com/read/20161102/12/598488/peluang-usahaspecialty-coffee-jadi-potensi-pengembangan-di-indonesia. Diakses 2 Juli 2019. 
ICCRI, 2016. Pelatihan Uji Cita Rasa Kopi https://tc.iccri.net/2016/07/15/formulirpendaftaran-uck-2019/ Diakses 2 Juli 2019.

INDIKASI GEOGRAFI TERDAFTAR, 2016. http://www.dgip.go.id/images/ki-images/pdffiles/indikasi geografis/IG\%20Terdaftar\%20+\%20LOGO\%20update\%20JAn $\% 2020$ 18.pdf. Diakses 9 Juli 2019.

OKEZONE. 2016. Mengulik Prestasi Kopi Premium Indonesia di Dunia. https://economy.okezone.com/read/2016/03/30/320/1349250/menqulik-prestasikopi-premium-indonesia-di-dunia. Diakses 7 Juli 2019.

OTTENCOFFEE, 2016. Kopi Specialty VS Komersi: Apa Bedanya? https://majalah.ottencoffee.co.id/kopi-specialty-vs-komersil-apa-bedanya/. Diakses 12 Juli 2019

PUSDATIN PERTANIAN, 2106. Out Look Kopi. http://www.perpustakaan.bappenas.go.id/lontar/file?file=digital/167009[ Konten ]...pdf. Diakses 2 Juli 2019

SCAA, 2015. SCAA Protocols. https://www.scaa.org/PDF/resources/cupping-protocols.pdf. Diakses 15 Juli 2019

YUSIANTO, 2017. Peranan Uji Cita Rasa dalam Industri Perkopian. http://www.tpsaproject.com/wp-content/uploads/2017-03-13-Presentation-61123.03b.pdf. Diakses 7 Juli 2019. 